\title{
A REVISTA A MENSAGEIRA E A PROPOSTA DE EDUCAÇÃO DA MULHER BRASILEIRA
}

A MENSAGEIRA MAGAZINE AND THE EDUCATIONAL PROPOSITION FOR THE BRAZILIAN WOMAN

Cristina Loff Knapp ${ }^{1}$

1 Docente da Universidade de Caxias do Sul - UCS.

Via Atlântica, Sâo Paulo, n. 39, p. 9-38 set. 2021. doi: $10.11606 / v a .139 .180858$ 
Resumo: 0 objetivo de nosso estudo é discutir como a revista $A$ Mensageira foi propulsora da educação feminina nos lares brasileiros, por meio de seus escritos. Para tanto, nosso corpus de estudo será alguns artigos publicados no periódico, em sua edição fac-similar. Nossa pesquisa terá como referencial teórico os estudos de Luca (1999) e Kamita (2004) a respeito da Mensageira. Sobre a imprensa feminista serão levados em consideração os escritos de Duarte (2017), Perrot (2008) e Priore (2004). Nossa intenção é apresentar como os textos publicados por Presciliana Duarte de Almeida e Júlia Lopes de Almeida evidenciavam que a instrução era necessária ao sujeito feminino.

Palavras-chave: Educação, século XIX, mulher, $A$ mensageira. 
Abstract: The objective of this study is to discuss how A Mensageira ("The Messenger" in English) magazine was a mechanism to motivate education for women in Brazilian homes, by means of its writings. To do so, our study corpus consists of a few articles from the publication, in its facsimile edition. Our research uses the theoretical references of Luca (1999) and Kamita (2004) about A Mensageira. As regards to the female press we consider the writings of Duarte (2017), Perrot (2008) and Priore (2004). Our aim is to demonstrate how the texts by Presciliana Duarte de Almeida and Júlia Lopes de Almeida highlighted the need for instruction for women.

Keywords: Education, nineteenth century, woman, $A$ mensageira. 
Quereis civilizar uma nação? Educae a mulher.

José Américo dos Santos (1897).

\section{Introdução}

O século XIX foi o palco de grandes modificações, principalmente na sociedade que teve a burguesia em ascensão. Com isso, a mulher adquire um novo destaque nela, como a centralizadora da educação familiar e da sociedade, por meio do magistério. É nesse período, no Brasil, que emergem publicações na imprensa com escritos de autoria feminina e dirigidos por mulheres. Isso foi uma conquista significativa na luta pela igualdade de direitos.

Nessa perspectiva, objetivamos discutir como a revista $A$ Mensageira foi propulsora da educação feminina no Brasil, por meio de seus artigos e crônicas. Para tanto, balizaremos nosso estudo nos escritos de Luca (1999), Kamita (2004), Duarte (2017) sobre a imprensa feminista e Priore (2004) e Perrot (2008) a respeito da condição feminina na sociedade.

\section{Século XIX}

O século XIX presenciou a ascensão da família burguesa e, com isso, a mulher assumiu o lugar de organizadora desse novo ambiente familiar, sendo 
responsável pela educação dos filhos. Aliás, essa era alicerçada nos herdeiros, na culinária, em bordados e entre outras coisas dedicadas à casa. Como houve a reorganização das cidades, dos estados, das ruas, enfim, os burgueses passaram a ocupar um lugar que antes era somente da aristocracia, as residências tiveram mudanças e priorizavam o convívio familiar e a intimidade do casal. Os mais ricos abriram suas casas a fim de receber pessoas, amigos, entes queridos e outros. Maria Ângela D'Incao (2004) assinala que:

Nesses lugares, a ideia de intimidade se ampliava e a família, em especial a mulher, submetia-se à avaliação e opinião dos "outros". A mulher de elite passou a marcar presença em cafés, bailes, teatros e certos acontecimentos da vida social. Se agora era mais livre - "a convivência social dá maior liberalidade às emoções" -, não só o marido ou o pai vigiavam seus passos, sua conduta era também submetida aos olhares atentos da sociedade. Essas mulheres tiveram de aprender a comportar-se em público, a conviver de maneira educada. (D' INCAO, 2004, p.191)

Como a sociedade burguesa estruturou-se de modo diferente, exigiu-se da mulher o desenvolvimento de algumas habilidades a serem apresentadas não somente aos seus pretendentes, mas também em seu convívio social. Com isso, a educação para as moças modificou-se, indo além dos cuidados com o lar e com os filhos. As aulas de piano, canto e outras habilidades foram ensinadas com a intenção de conquistarem um esposo com condição social mais elevada. 
No entanto, as jovens ainda eram retiradas da escola antes do homem e o ensino tinha um objetivo: conquistar um bom casamento.

Esse período de ascensão burguesa, no Brasil, contribuiu para a solidificação do hábito de leitura entre as mulheres. Muitas dedicavam-se a ler romances, visto que o século XIX figura como o período de ascensão do gênero. Sobre as leituras D’Incao (2004) salienta que:

As leituras animadas pelos encontros sociais, ou feitas à sombra das árvores ou na mornidão das alcovas, geraram um público leitor eminentemente feminino. A possibilidade do ócio entre as mulheres de elite incentivou a absorção das novelas românticas e sentimentais consumidas entre um bordado e outro, receitas de doces e confidências entre amigas. As histórias de heroínas românticas, langorosas e sofredoras acabaram por incentivar a idealização das relações amorosas e das perspectivas de casamento. (D'INCAO, 2004, p.191)

A partir desse período, foram ganhando força os escritos de autoria feminina, juntamente com a luta pelo direito à educação. Algumas mulheres que viviam reclusas, principalmente as que se dedicavam a vida religiosa, de certa forma, conseguiam escrever. Perrot esclarece que os conventos "eram lugares de abandono e de confinamento, mas também refúgios contra o poder masculino e familiar. Lugares de apropriação do saber, e mesmo de criação" (PERROT, 2008, p. 84). Lobo (1997) reforça essa afirmação de 
Perrot ao elucidar que os conventos foram lugares para se poder desenvolver a educação e a leitura:

Ser o outro, o excluso, o estranho é próprio da mulher que quer penetrar no "sério" mundo acadêmico ou literário. Não se pode ignorar que, por motivos mitológicos, antropológicos, sociológicos e históricos, a mulher foi excluída do mundo da escrita - só podendo introduzir seu nome na história europeia por assim dizer através de arestas e frestas que conseguiu abrir através de seu aprendizado de ler e escrever em conventos. (LOBO, 1997, p. 5)

Duarte (2017) argumenta que a partir do momento em que a leitura e a escrita entraram no cotidiano das mulheres, ocuparam lugar em suas vidas. Dessa forma, surgiu a crítica e o questionamento da sua condição. Observa-se que isso só foi possível pela leitura, pois despertou a consciência "da condição subalterna a que o sexo estava submetido, e proporcionou o surgimento de escritos reflexivos e engajados" (DUARTE, 2017, p. 14).

0 acesso à educação foi uma importante via de inserção da mulher no meio letrado, no século XIX. 0 artigo Mulheres na sala de aula, de Guacira Lopes Louro (2004), destaca o quão relevante o magistério foi como elemento propulsor da inserção delas em um novo ambiente, fora do doméstico:

A identificação da mulher com a atividade docente, que hoje parece a muitos tão natural, era alvo de discussões, disputas e polêmicas. Para alguns pare- 
cia uma completa insensatez entregar às mulheres usualmente despreparadas, portadoras de cérebros "pouco desenvolvidos" pelo seu "desuso" a educação das crianças. [...] Outras vozes surgiam para argumentar na direção oposta, afirmavam que as mulheres tinham, "por natureza", uma inclinação para o trato com as crianças, que elas eram as primeiras e "naturais educadoras", portanto nada mais adequado do que lhes confiar a educação escolar dos pequeninos. (LOURO, 2004, p. 376)

Louro (2004) também esclarece que os homens eram responsáveis por educar os meninos, e as mulheres, as meninas; contudo aos primeiros cabia ensinar geometria e as jovens bordado e costura. Isso notabiliza o preconceito de gênero. 0 ensinamento dedicado às disciplinas mais lógicas estava a serviço do homem, enquanto que a mulher dedicava-se apenas às atividades domésticas. Como pontua Tambara:

Na verdade, o processo educacional no Brasil sempre apresentou tendência a uma educação diferenciada, se não oficialmente, pelo menos decorrente da impregnação de uma concepção social em que se atribui específica divisão sexual da educação. Por exemplo atribuindo ao sexo masculino áreas ditas "científicas" e ao feminino "áreas humanísticas". (TAMBARA, 1997, p. 87)

Ainda explana Louro (2004, p. 371) que a conduta das professoras e o seu ambiente familiar deveria ser exemplar, "pessoas de moral inatacável". A moral masculina nunca era questionada, herança de uma 
cultura patriarcal, elevando apenas a inteligência do homem e renegando a mulher a educação. A escritora Nísia Floresta salienta que "a educação da mulher muita influência tem sobre a moralidade dos povos e que é o elo característico mais saliente de sua civilização" (FLORESTA, 1989, p. 46). A autora combateu o preconceito em relação à educação do sujeito feminino.

Não podemos deixar cair no esquecimento a diferenciação bem grande que havia em relação às classes sociais, visto que as moças de classes mais abastadas aprendiam o piano e o francês. Louro afirma que:

As habilidades com a agulha, os bordados, as rendas, as habilidades culinárias, bem como as habilidades de mando das criadas e serviçais, também faziam parte da educação das moças; acrescida de elementos que pudessem torná-las não apenas uma companhia mais agradável ao marido, mas também uma mulher capaz de bem representá-lo socialmente. (LOURO, 2004, p. 373)

Nísia Floresta em seus escritos apresenta considerações sobre a diferenciação que houve no ensino em escolas públicas e privadas no século XIX, principalmente, na formação das futuras professoras, trazendo à tona a mercantilização do ensino. Segundo Floresta:

Uma casa de educação entre nós é em geral, uma especulação como qualquer outra. Calcula-se de antemão o número dos alunos prometidos ou em perspectiva, as vantagens que podem resultar de uma rigorosa 
economia, em que por vezes a manutenção daqueles é comprometida. (FLORESTA, 1989, p. 78)

As diferenças sociais, étnicas e religiosas também influenciavam no acesso à educação. Para as crianças negras, como considera Louro, (2004) " a educação se dava na violência do trabalho e nas formas de luta pela sobrevivência" (LOURO, 2004, p. 372), ou a partir de iniciativas de cunho filantrópico. A autora também informa que os indígenas não tinham acesso à escola. As crianças eram educadas pelo seu próprio povo e não lhes era permitido frequentar colégios. Já as diferentes etnias de origem alemã, italiana, espanhola e japonesa tinham escolas para meninos e para meninas, construídas, muitas vezes, com o incentivo de seus países de origem. Sabe-se que nas classes menos favorecidas, de operários, as meninas primeiro deveriam ajudar a cuidar dos irmãos, da casa, para somente depois, em última instância, se pensar em educá-las.

A formação cristã também fez parte da educação destinada às moças, no período em questão, assim como algumas ideias positivistas e cientificistas, como comenta Louro (2004). Além dessas reflexões sobre a educação destinada ao sujeito feminino, Louro, atenta para a formação docente no período, o século XIX. A maioria dos docentes, e isso não aconteceu apenas na sociedade brasileira, eram homens. Com o processo de industrialização e modernização das indústrias 
e com a ampliação do comércio, as mulheres começaram a ocupar o espaço antes masculino.

A inserção da mulher no meio docente gerou algumas controvérsias. Existia os que defendiam que a docência deveria ser exercida por elas, afirmando que a atividade de ensinar "era uma extensão da maternidade" (LOURO, 2004, p. 376). Sobre isso, a autora registra que:

0 argumento parecia perfeito: a docência não subverteria a função feminina fundamental, ao contrário, poderia ampliá-la ou sublimá-la. Para tanto seria importante que o magistério fosse também representado como uma atividade de amor, de entrega e doação. A ele acorreriam aquelas que tivessem "vocação". (LOUR0, 2004, p. 376)

O contrário também acontecia, pessoas que acreditavam que a mulher não poderia ensinar, pois seu intelecto era próximo ao de uma criança ou, então, pensavam que viviam voltadas para o passado. Enfim, esse pensamento foi ficando em segunda posição a partir do momento em que as meninas frequentaram os cursos de magistério e os homens começaram a deixar a docência. Assim, alguns cuidados foram instituídos, a fim de proteger o sujeito feminino que lecionavam para meninos também. Sobre isso, Louro focaliza:

As jovens normalistas, muitas delas atraídas para o magistério por necessidade, outras por ambicionarem 
ir além dos tradicionais espaços sociais e intelectuais, seriam também cercadas por restrições e cuidados para que sua profissionalização não se chocasse com sua feminilidade. (LOURO, 2004, p. 379)

Sabe-se que muitas pessoas defendiam que o trabalho feminino deveria ser abandonado quando a mulher fosse constituir uma família, por isso entendiam o magistério como algo transitório. As escolas normais, como eram chamadas as instituições destinadas a prepararem as moças para o magistério, foram crescendo. Louro acentua que, mesmo a maioria dos docentes sendo mulheres, a direção era masculina:

Com exceção das escolas mantidas por religiosas onde as madres ocupavam posição superior, nas escolas públicas, foram os homens que detiveram por longo tempo as funções de diretores e inspetores. Reproduzia-se e reforçava-se, então, a hierarquia doméstica: as mulheres ficavam nas salas de aulas, executando as funções mais imediatas do ensino, enquanto os homens dirigiam e controlavam todo o sistema. A eles se recorria como instância superior, referência de poder; sua presença era vista como necessária exatamente por se creditar à mulher menos firmeza nas decisões, excesso de sentimento, tolerância etc. Aos homens eram encaminhados os alunos problema ou qualquer outra questão que exigisse a tomada de decisões de problemas mais graves. (LOURO, 2004, p. 384)

Com o passar dos anos, isso tudo foi mudando e as mulheres assumiram também cargos de direção e 
coordenação, sendo admiradas pelas professoras e futuras docentes. "Dessa forma, algumas delas acabaram por imprimir marcas extremamente pessoais às instituições que dirigiram, criando escolas". (LOURO, 2004, p. 385). Assim, o magistério foi marcado pela presença feminina. Hahner argumenta a respeito disSo:

A coeducação também desempenhou um papel na feminização da instrução primária no Brasil. Criou mais oportunidades para mulheres entrarem no magistério porque se podia confiar a regência das aulas mistas às mulheres, e não limitá-las a só lecionar nas escolas para meninas. E a introdução da coeducação nas escolas normais aumentaria o número de mulheres e diminuiria o número de homens matriculados, mudando, assim, o futuro caráter da magistratura. (HAHNER, 2011, p. 468-469)

Ainda conforme aponta Hahner (2011, p. 472), o ensino primário brasileiro levou muito anos para aceitar a feminização. Embora as mulheres fossem a maioria docente, os cargos de supervisão, diretoria e até de organização de leis para o ensino foram por muitos anos desempenhados por homens. Nas palavras de Hahner "ainda que os homens tivessem saído das salas de aula, não saíram do poder sobre o ensino" (HAHNER, 2011, p. 472).

Contudo, como já salientamos, a mulher só passou a ocupar um lugar de destaque no ensino quando a leitura e a escrita assumiram a posição de realce 
no universo feminino. Zinani (2012, p. 310) chama a atenção para a importância da literatura, a fim de discutir conceitos já estabelecidos pela sociedade androcêntrica. Isso tudo só foi possível, segundo a autora (2012), por meio da apropriação de um discurso que evidenciava a busca pela igualdade de direitos na sociedade.

O século XIX também foi marcado pela inserção do sujeito feminino no mundo editorial. Além de professoras, que precisavam ser instruídas, as mulheres, no geral, foram apresentadas ao gênero romance ou, então, às inúmeras publicações de revistas e jornais que tinham textos de autoria feminina, inclusive alguns foram dirigidos por mulheres. É caso da revista A Mensageira, objeto de nosso estudo, que defendeu a educação do sujeito feminino em muitos de seus artigos.

\section{A Mensageira comprometida com a educação da mulher brasileira}

A revista A Mensageira circulou na cidade de São Paulo, entre os anos de 1897 e 1900 . Era publicada quinzenalmente, no primeiro ano, todavia, a partir de 1899, passou a ser mensal e contou com 36 edições. Seu conteúdo era textos em prosa ou verso, tendo como primordial objetivo a divulgação de artigos que se preocupavam com a posição da mulher na sociedade e com a sua instrução. Em 1987, a Secretaria 
do Estado da Cultura e a Imprensa Oficial do Estado de São Paulo publicaram uma edição fac-similar da revista em dois volumes, proporcionando o resgate desse material. Em nosso estudo, vamos utilizar essa edição. Luca (1999) registra que, em 1902, Presciliana Duarte de Almeida doou a coleção completa para a hemeroteca do Instituto Histórico e Geográfico de São Paulo, possibilitando organizar a edição de 1987.

Essa publicação está organizada em dois volumes, trazendo os 36 fascículos. Luca (1999) indica que, no primeiro volume, são apresentados os números que tiveram tiragem quinzenal, ou seja, os 24 primeiros que compreendem o período de 15 de outubro de 1897 a 30 de setembro de 1898. Já no segundo volume, os de tiragem mensal, com 12 números, que circularam entre fevereiro de 1899 a janeiro de 1900 . Segundo Rosana Cássia Kamita:

A revista $A$ Mensageira preocupava-se em defender uma educação de qualidade para as mulheres. A princípio os textos eram fundamentados em argumentos que de certa forma corroboravam com o preconceito em relação à mulher, ou seja, a educação feminina era defendida porque assim ela teria condições de exercer com maior competência seu papel de mãe e criar filhos que seriam melhores cidadãos. Em um segundo momento, no entanto, os argumentos pautavam-se na necessidade de uma educação à mulher que lhe permitisse participar do mercado de trabalho, ideal partilhado por muitas feministas da época, que consideravam esse o caminho para a autonomia feminina econômica e intelectual. (KAMITA,2004, p. 164) 
Kamita procura acentuar a relevância do periódico para a época e para a posterioridade. Era um espaço de reflexão, no qual as mulheres que estavam à frente de seu tempo podiam expressar seus sentimentos e opiniões com a intenção de garantir um futuro melhor. A literatura era e ainda é a arte da reflexão, da recriação da realidade. 0 periódico era destinado somente às mulheres, embora existissem colaboradores masculinos. As colaboradoras da revista A Mensageira eram 33 mulheres, chamadas de mensageiras, dentre elas estavam: Júlia Lopes de Almeida, Cândida Fortes, Julieta de Mello Monteiro e sua irmã Revocata Heloísa de Mello, Áurea Pires, Ibrantina Cardona, entre tantos outros nomes. 0 papel importante da diretora da revista, Presciliana Duarte de Almeida, é elucidado por Martins:

A capacidade aglutinadora de Presciliana fez daquela publicação o espaço por excelência da mulher escritora da virada do século [...]. Da busca de comportamentos à produção literária feminina [...] percebida como o mais importante veículo de divulgação da poesia feminina. Divulgava a opinião e a colaboração das mulheres envolvidas com as letras. (MARTINS, 2001, p. 375)

Duarte (2017) elucida que a revista $A$ Mensageira se destacava das outras publicações da época visto que procurava incentivar a emancipação feminina, a igualdade de direitos, diferenciando-se de outras publicações femininas, as quais divulgavam receitas 
ou moda. A diretora do periódico, Presciliana, deixou claro, no editorial do primeiro número, o objetivo da revista:

Ora, esse desenvolvimento intellectual da mulher brazileira não se haverá cingido unicamente ao grupo das que surgem á tona, apparecendo na imprensa ou nos cursos de ensino superior. Havemos convir em que o seu desenvolvimento collective deve ter sido enorme para que tantas se tenham podido individualisar e excitar a admiração dos contemporâneos. Assim, ao emprehendermos esta publicação, sentimo-nos animadas da mais viva esperança, depositada no espirito progressivo e na benemerencia de nossas compatriotas. (ALMEIDA, 1987, p. 1)

0 texto pretende dar voz às mulheres, a fim de lutarem pelos seus direitos, e levar até os lares literatura escrita pelas mulheres. Mencionamos que o subtítulo da revista era "revista literária dedicada à mulher brasileira", frisando muito claramente o seu público. Além disso, na coluna "Entre amigas", a escritora Júlia Lopes de Almeida também destaca o ideário da publicação e procura enfatizar a importância do desenvolvimento intelectual feminino. Conferimos:

A mulher brazileira conhece que pode querer mais, do que até aqui tem querido; que pode fazer mais, do que até aqui tem feito. Precisamos comprehender antes de tudo e affirmar aos outros, atados por preconceitos e

2 As citações retiradas da revista serão transcritas de acordo com a grafia original e estão na edição fac-similar publicada pela Secretaria do Estado da Cultura e Imprensa Oficial do Estado de São Paulo em 1987. 
que julgam toda a liberdade de acção prejudicial á mulher na familia, que é a bem da própria familia, principalmente d'ella, que necessitamos de desenvolvimento intelectual e do apoio seguro de uma educação bem feita. Os povos mais fortes, mais práticos, mais activos, e mais felizes são aquelles onde a mulher não figura como mero objecto de ornamento; em que são guiadas para as vicissitndes da vida com uma profissão que ampare num dia de lucta, e uma boa dose de noções e conhecimentos solidos que lhe aperfeiçõem as qualidades moraes. (ALMEIDA, 1987, p. 3)

A citação de Júlia Lopes de Almeida procurou enfatizar a relevância da educação para a mulher, a fim de poder auxiliar seus filhos, pois "uma mãe instruída marcará no espirito do seu filho, o sentimento da ordem, do estudo e do trabalho, de que tanto carecemos. Parece-me que são esses os elementos de progresso e de paz para as nações" (ALMEIDA, 1987, p. 3). Frisamos que as afirmações corroboram o que era defendido no editorial da revista por sua diretora. Todavia, fica claro nas páginas d'A Mensageira que a educação da mulher não era apenas destinada à educação de seus filhos, mas também à luta pela igualdade de direitos.

No entanto, também é sabido que quanto mais educação a mulher tiver, mais consciência de sua inferioridade ela terá, e, assim, mais condições de reivindicar seu lugar na sociedade. Quando se passa a instruir alguém, esse alguém também compartilha da mesma posição. Esse ideal de educação, para que a 
mãe pudesse instruir melhor os filhos, vai ao encontro do que Nísia Floresta declara:

Uma mãe bem-educada e suficientemente instruída para dirigir a educação de sua filha obterá sempre maiores vantagens, aplicando-se com terna solicitude a inspirar-lhe como emulação o sentimento da própria dignidade, que qualquer diretora não conseguiria obter de suas educandas. (FLORESTA, 1989, p.9)

Algo peculiar do periódico dirigido por Presciliana era a publicação de escritos de autoria masculina, como na coluna intitulada "Cartão de Parabéns", de autoria de Silvio de Almeida. Observemos:

Esta revista apparece aos olhos, talvez espantados da velha educação burgueza, como um brado eloquente em favor da emancipação intellectual do eterno e doce feminino, que aprendemos a extremecer no olhar de bençam de nossas mães, santificadas no culto da mais nobre veneração pelos seus sacrifícios, e acabamos finalmente por idealisar no paraiso terrestre do sorriso de felicidade de nossas esposas amoraveis. (ALMEIDA, 1987, p. 10)

O periódico era composto por textos de autoria feminina, porém alguns homens também publicavam, como afirma Luca (1999), apenas $3 / 4$ ou 4/5 dos escritos de um volume. Os colaboradores masculinos consolidavam o ideal da revista e defendiam que o sujeito feminino não deveria apenas ficar restrito às lidas domésticas, mas também escrever e publicar, 
como Sílvio Almeida declara: se aventurar n'“a vida superior do espírito". É importante reforçarmos que o mesmo autor apresentou considerações relevantes, no segundo número da revista, a fim de explicar mais uma vez os escritos de autoria masculina em uma revista que deveria priorizar apenas a voz silenciada da sociedade. Conferimos:

Arthur Azevedo, em sua Palestra de 21, aconselha a directora da Mensageira a supprimir a collaboração de homens, para quee esta revista adquira uma nota mais original e sympathica. Sentimos discordar completamente, neste ponto, do notável homem de letras que tão assignaladamente abrilhanta as columnas do Paiz. Em primeiro logar, já não seria uma originalidade e mesmo aqui no Brazil, uma publicação periodica exclusivamente feita por mulheres; e, por outro lado, parece-nos que em nada se apouca a sympathia desta revista por admittir em suas columnas algumas pennas masculinas. Os melhores salões estão sempre abertos aos dois sexos, e a absoluta exclusão dos marmanjos só se poderia exigir em um convento de freiras. Si o proprio Paiz, que é um jornal militante e forte, nunca se negou ás escriptoras, por que razão havia de excluir aos homens a Mensageira, que deve ser toda gentil? (ALMEIDA, 1987, p. 23-24)

A partir da leitura do excerto do artigo de Almeida, auferimos que a revista não pretendia restringir as suas publicações apenas às mulheres. Os escritos de autoria masculina também eram bem-vindos, estando claro que não poderiam ferir o ideal defendido na revista. Ressaltamos os argumentos iniciais da publicação na voz da estudiosa Kamita: 
Não é uma publicação, como outras do período que destacavam assuntos como trabalhos manuais, moda, culinária, puericultura. A intenção era a de discutir questões relativas à emancipação da mulher, com a veiculação de textos literários, artigos que tratassem do tema, além dos editoriais com a reflexão crítica acerca da situação feminina. (KAMITA, 2004, p. 164)

A citação de Kamita discute a emancipação do sujeito feminino por meio da ascensão do seu trabalho, e sabemos que as mulheres de classes menos favorecidas eram empregadas em indústrias, comércios, enfim, desenvolviam alguma atividade que lhes pudesse garantir um salário para ajudar no sustento da família. Contudo, para as pertencentes à burguesia trabalhar fora era mais difícil, e o magistério surgiu como uma possibilidade de instrução e uma forma de luta pelos seus direitos. Por isso, podemos ver a importância de periódicos que objetivavam divulgar escritos de autoria feminina e defendessem a sua instrução.

Ibrantina Cardona, uma das 33 colaboradoras da revista, também defendeu a instrução da mulher e a possibilidade do trabalho fora do ambiente doméstico. Em uma carta, dedicada à Presciliana Duarte de Almeida, publicada em 15 de novembro de 1897, a escritora assinala que:

[...] aqui está, sobre a minha mesa de trabalho, A Mensageira, cujo programma revela o mais louvável tentamen de um espirito superior, em favor da instrucção; aqui estão os preciosos fructos intellectuaes das pen- 
sadoras que acompanham a marcha do progresso, sob o labaro triumphal da Arte. (CARDONA, 1987, p. 38)

A partir da citação de Cardona, reforçamos como a educação feminina era uma das bandeiras da revista $A$ Mensageira. Várias colaboradoras defendiam o estudo como uma forma da mulher conquistar o seu espaço negado e silenciado na sociedade patriarcal.

No exemplar de número quatro, publicado em 30 de novembro de 1897, é possível ler uma coluna intitulada "Selecção", de José Américo dos Santos, cujo tema central é a educação feminina. 0 autor deixou claro seu pensamento a respeito da educação para ambos os sexos. Em suas palavras: "Quereis civilizar uma nação? Educae a mulher” (SANTOS, 1987, p. 57). Observemos mais um trecho:

0 grão de educação da mulher pode ser considerado a justo titulo como a pedra de toque da civilisação de um povo. A mulher confiou a natureza a sublime missão de acompanhar desde os primeiros momentos de vitalidade, o desenvolvimento dos indivíduos, cuja reunião constitue a sociedade humana. Ella imprime-lhes desde o berço as primeiras ideias, que por toda a vida lhes ficam gravadas na mente e cuja elevação depende do grão de educação. A influencia, que tão fortemente ella exerce sobre a humanidade, sobejamente justifica a necessidade de prover a sua educação. (SANTOS, 1987, p. 57)

Na longa citação, é possível constatar como o autor defendeu a educação feminina, visto que tem o 
poder de influenciar àqueles que convivem com ela desde o seu nascimento, ou seja, os filhos, corroborando mais uma vez o que defendia Nísia Floresta. Contudo, sabemos que não é somente por isso que a educação é necessária, mas também, como já mencionamos por meio da assertiva de Duarte, para que elas tenham consciência de seu papel submisso perante à sociedade.

Por isso, os periódicos tiveram uma grande relevância no período, século XIX, não somente no Brasil, mas em outros países. É o momento no qual a literatura que questiona, que não aceita tudo como verdade absoluta, passa a ser divulgada. Claro que muitas mulheres tiveram grande dificuldade em publicar. Muitas escreveram sob pseudônimos, inclusive masculinos, para serem melhor aceitas no meio editorial. Duarte e Paiva (2009) focalizam sobre a atuação da mulher na imprensa:

A representação da mulher de letras na imprensa nas primeiras décadas de 1900 evidencia o ambiente muitas vezes hostil e pouco acolhedor para a mulher que buscava reconhecimento entre os intelectuais de seu tempo, bem como nos possibilita refletir sobre a construção do que se costumou nomear como o feminino. (DUARTE; PAIVA, 2009, p. 15)

Mesmo com um ambiente hostil, elas não desistiram e, na medida do possível, se posicionaram e reivindicaram cada vez mais os seus direitos. A revista 
A Mensageira foi uma espécie de divulgadora não somente da escrita de autoria feminina, mas também na defesa da educação da mulher. E isso aparecem em vários números, seja na escrita de homens, como na de mulheres. Vejamos mais um trecho de um artigo da mensageira Maria Emília, publicado na edição de número 2, de 30 de outubro de 1897:

Sempre que se fala em modificar a educação da mulher ou ampliar os seus meios de acção, aparece alguem que faça a apologia da mulher como rainha que deve ser... pela fraqueza! Que o encanto da mulher está justamente na sua ignorancia, na sua timidez, na sua infantilidade! Pensem assim ou não, entretanto, queiram ou não queiram, a mulher instruida, forte, capaz de velar á cabeceira de um filho enfermo, auxiliando as perscrustações, da sciencia; ou de repellir com energia as chalaças de qualquer imbecil, será e mulher do futuro, será a verdadeira companheira do homem, que sabe participar de todos seus pensamentos e ajudal-o em todas as resoluções diffices. A posição negligente de tutelada deixará de existir quando a mulher comprenhender que sobre seus hombros pesam tambem as responsabilidades sociaes. (EMILIA, 1987, p. 17)

Nesse longo trecho do artigo de Maria Emília, intitulado "Falso encanto", constatamos um pouco da defesa da instrução feminina para auxiliar na educação dos filhos e na conciliação de conflitos familiares. A mulher deveria ser atuante na família e não apenas ocultar-se ou permanecer calada. A educação defendida por Maria Emília busca dar voz e decisão ao sujeito feminino no seu meio, com a sua família, deixan- 
do de lado a vida "sossegada" que muitas preferiam levar. Ideia um pouco diversa da autora Júlia Lopes de Almeida, no artigo "Entre amigas", publicado no dia 15 de outubro de 1897 e já mencionado anteriormente. Vejamos um trecho referente à educação feminina:

Esta revista, dedicada ás mulheres, parece-me dever dirigir-se especialmente ás mulheres, incitando-as ao progresso, ao estudo, á reflexão, ao trabalho e a um ideal puro que as nobilite e as enriqueça, avolumando os seus dotes naturaes. Ensinará que, sendo o nosso, um povo pobre, as nossas aptidões podem e devem ser aproveitadas em variadas profissões remuneradas e que auxiliem a familia, sem detrimento do trabalho do homem. Temos poucas medicas, e mesmo escriptoras, se não temos de menos, também não temos de mais (e entre parenthesis: a Mensageira que abra os olhos ás senhoras que pensam que se pode escrever com a mesma facilidade com que se pode fazer creme de laranja ou manjar branco, coisas aliás delicadas); temos já algumas senhoras empregadas no telegrepho, no commercio, e nas industrias e artes, mas a porcentagem é tão diminuta que nem vale o alludir-se a ella. (ALMEIDA, 1987, p. 4-5)

Esse outro trecho do artigo de Júlia Lopes de Almeida exibe a preocupação da autora em trazer à tona profissões que a mulher pode assumir no mercado de trabalho, a fim de aumentar a renda familiar, dividindo, dessa forma, com o homem o sustento de todos os integrantes de seu lar. Também fica muito marcado a opinião da autora a respeito da revista $A$ Mensageira: fomentar o estudo entre as mulheres, como forma de ascensão social, de busca dos seus direitos e de igual- 
dade entre homens e mulheres. Tudo feito a partir da instrução do sujeito feminino.

\section{Ccomsideração finais}

Com isso, podemos auferir que a revista $A$ Mensageira teve como um dos seus grandes objetivos a educação da mulher. Na verdade, o periódico foi lócus de resistência de vozes femininas silenciadas que estavam ecoando em prol da igualdade de direitos, um deles o da educação.

O século XIX foi de grandes transformações, e a ascensão da burguesia possibilitou que as mulheres assumissem outros papeis na sociedade, não somente o de dona do lar e responsável pelos filhos. 0 boom do gênero romance pode ter sido um dos fatores que inseriu o sujeito feminino no universo da leitura, com ela, a mulher passou a ter mais consciência do seu lugar na sociedade.

Assim, o sujeito feminino pode reivindicar o direito à educação e a leitura passou a fazer parte desse universo das mulheres, como já mencionamos. Lembrando que nesse período a educação brasileira era muito precária. 0 ensino primário era ofertado às mulheres, contudo, o secundário não era uma preocupação do governo, restringindo-se às esferas particulares. Por isso, poucas tinham acesso a ele.

Com a leitura em ascensão, a escrita de autoria feminina também passou a ser relevante, principal- 
mente por trazer à luz as vozes silenciadas pelo patriarcalismo. Muitas publicações vieran à tona, como jornais, revistas e livros, trazendo em suas páginas reflexões a respeito da instrução da mulher, como elemento fundamental também para a educação dos filhos. Assim, elas foram se inserindo no mercado de trabalho, podendo ter acesso ao mundo que antes era somente masculino.

Dessa forma, a revista A Mensageira entra em cena com a perspectiva de levar aos lares brasileiros literatura escrita por mulheres e o incentivo à educação e ao profissionalismo, cujo foco é não somente a instrução dos filhos ou a conquista um bom marido, mas para se ter uma profissão e conquistar seu lugar na sociedade, como podemos constatar em vários artigos do periódico. Com isso, reafirmamos o quão significante foi $A$ Mensageira para a divulgação da educação feminina no século XIX, no Brasil, visto que levava aos lares femininos, em suas páginas crônicas, contos, poemas e editoriais, a intenção de tocar o universo feminino com textos literários. Assim, a mulher passa a buscar a sua identidade na sociedade androcêntrica e a refletir sobre a sua condição de silenciamento. 


\section{Referências}

ALMEIDA, Júlia Lopes de. Entre amigas. In: ALMEIDA, Presciliana D. de (ed). A Mensageira: revista literária dedicada à mulher brasileira. Edição fac-similar. São Paulo: Imprensa Oficial do Estado: Secretaria de Estado da Cultura: São Paulo, 1987. v. I, p. 3-5.

ALMEIDA, Presciliana Duarte de. Duas Palavras. In: ALMEIDA, Presciliana Duarte de (ed). A Mensageira: revista literária dedicada à mulher brasileira. Edição fac-similar. São Paulo: Imprensa Oficial do Estado: Secretaria de Estado da Cultura: São Paulo, 1987. v. I, p. 1-2.

ALMEIDA, Sílvio. Cartão de parabéns. In: ALMEIDA, Presciliana Duarte. de (ed). A Mensageira: revista literária dedicada à mulher brasileira. Edição fac-similar. São Paulo: Imprensa Oficial do Estado: Secretaria de Estado da Cultura: São Paulo, 1987. v. I, p. 10.

ALMEIDA, Sílvio. Traços Ligeiros. In: ALMEIDA, Presciliana D. de (ed). A Mensageira: revista literária dedicada à mulher brasileira. Edição fac-similar. São Paulo: Imprensa Oficial do Estado: Secretaria de Estado da Cultura: São Paulo, 1987. v. I, p. 24.

CARDONA, Ibrantina. Notas pequenas. In: ALMEIDA, Presciliana D. de (ed). A Mensageira: revista literária dedicada à mulher brasileira. Edição fac-similar. São Paulo: Imprensa Oficial do Estado: Secretaria de Estado da Cultura: São Paulo, 1987. v. I., p. 38.

D’INCAO, Maria Ângela. Mulher e família burguesa. In: DEL PRIORE, Mary (Org.). História das mulheres no Brasil. 7. ed. São Paulo: Contexto, 2004. p. 187- 201.

DUARTE, Constância Lima; PAIVA,Kelen Benfenatti. A mulher de letras: nos rastros de uma história. Ipotesi, v.13, n.2 Juiz de Fora, p. 11-19, jul./dez. 2009. Disponível em: https://www.ufjf.br/revistaipotesi/edicoes-anteriores/ v13n2/. Acesso em: 14 jun. 2020. 
DUARTE, Constância Lima. Imprensa feminina e feminista no Brasil: Século XIX: dicionário ilustrado. Belo Horizonte: Autêntica, 2017.

EMILIA, Maria. Falso encanto. In: In: ALMEIDA, Presciliana Duarte. de (ed). A Mensageira: revista literária dedicada à mulher brasileira. Edição fac-similar. São Paulo: Imprensa Oficial do Estado: Secretaria de Estado da Cultura: São Paulo, 1987. v. I, p. 17.

FLORESTA, Nísia. Opúsculo Humanitário. São Paulo: Cortez, 1989.

HAHNER, June Edith. Escolas mistas, escolas normais: a coeducação e a feminização do magistério no século XIX. Revista Estudos Feministas, Florianópolis, p. 467-474, mai./ ago. 2011. Disponível em: https://periodicos.ufsc.br/index.php/ref/article/view/S0104-026X2011000200010. Acesso em: 20/08/20.

KAMITA, Rosana Cássia. Revista "A Mensageira": alvorecer de uma nova era? Revista Estudos Feministas, Florianópolis, p. 164-168, set./dez. 2004. Disponível em: https:// periodicos.ufsc.br/index.php/ref/article/view/S0104026X2004000300018. Acesso em: 16 de jul. de 2019.

LOBO, Luiza. A literatura feminina na América Latina. Revista Brasil de Literatura. Ano 1. jul./set.1997. Disponível em: http://lfilipe.tripod.com/LLobo.html. Acesso em: 10 jun. 2020.

LOURO, Guacira Lopes. Mulheres na sala de aula. In: DEL PRIORE, Mary (Org.). História das mulheres no Brasil. 7. ed. São Paulo: Contexto, 2004. p. 371- 403.

LUCA, Leonora de. A mensageira: uma revista de mulheres escritoras na modernização brasileira. 1999. 581 f. Dissertação (Mestrado) - Curso de Mestrado em Sociologia, Universidade Estadual de Campinas, Instituto de Filosofia e Ciências Sociais, Campinas, 1999. Disponível em: http:// www.repositorio.unicamp.br/handle/REPOSIP/280414. Acesso em: 30 nov. 2019.

MARTINS, Ana Luiza. Revistas em revista: imprensa e práticas culturais em tempos de República, São Paulo 
(1890-1922). São Paulo: Edusp; Fapesp; Imprensa Oficial do Estado, 2001.

TAMBARA, Elomar. A educação feminina no Brasil ao final do século XIX. Revista História da educação. ASPHE/ FAE/UFPEL, Pelotas, p. 67-89, abr. 1997. Disponível em: https://seer.ufrgs.br/asphe/article/view/30628. Acesso em: $20 / 08 / 20$.

SANTOS, José Américo dos. Selecção. In: ALMEIDA, Presciliana Duarte de (ed). A Mensageira: revista literária dedicada à mulher brasileira. Edição fac-similar. São Paulo: Imprensa Oficial do Estado: Secretaria de Estado da Cultura: São Paulo, 1987. v. I, p.57.

PERROT, Michelle. Minha história das mulheres. São Paulo: Contexto, 2008.

ZINANI, Cecil Jeanine Albert. Escritura e leitura: o gênero em questão. In: ZINANI, Cecil Jeanine Albert; SANTOS, Salete Rosa Pezzi dos Santos. Da tessitura ao texto: percursos de crítica feminista. Caxias do Sul, EDUCS, 2012, p. 309-323. 